\title{
Complex Rehabilitation of Patients with Jaw Fractures
}

\author{
Bobamuratova $\mathrm{DT}^{1^{*}}$ and Boymuradov $\mathrm{SHA}^{2}$ \\ ${ }^{1}$ PhD Candidate (researcher), Department of Dentistry, Tashkent Medical Academy, Uzbekistan \\ ${ }^{2}$ Doctor of medical sciences, Department of Otolaryngology and Dentistry, Department of the head of the the \\ maxillofacial surgery, Tashkent Medical Academy, Uzbekistan
}

Received: July 23, 2018; Accepted: August 08, 2018; Published: August 24, 2018

*Corresponding author: Bobamuratova DT, PhD Candidate (researcher), Department of Dentistry, Tashkent Medical Academy, Uzbekistan, 100109, Tel: +99897 7105911; E-mail: dbobamuratova@mail.ru

\begin{abstract}
This review article provides brief information on rehabilitation measures that improve the local and general condition of patients with jaw fractures.

In the recent year the number of injuries with maxillofacial trauma has significantly increased in all countries of the world. Among maxillofacial injuries, fractures of the jaws occupy the main place (65$80 \%$ ), and most of the patients are young and able-bodied people. Despite the continuous improvement of the treatment methods of jaw fractures, the periods of immobilization and temporary disability are not reduced, and the incidence of inflammatory complications remains high, which significantly worsens the outcome of trauma. This largely depends on the lack of an effective system of rehabilitation of patients and a comprehensive approach to treatment with the use of both, pharmacological, psychotherapeutic, and physical rehabilitation measures. Complex treatment and rehabilitation of patients with jaw fractures will promote rapid stabilization and reduction of posttraumatic manifestations of the disease and, as a result, improve physical and mental health and increase the life potential and the level of their working capacity.
\end{abstract}

The object of the review is to study and combine rehabilitation activities, that improve the health, working capacity and local status of patients with jaw fractures during immobilization and after removal of splints.

Materials: The articles were identified using the computerized search engine PubMed, Elsevier, Cochrane Central, Google scholar, Google search, Research Gate, Ebsco Host, dissercat.com, medical-diss. com, cyberleninka.ru and other possible sites with keywords such as maxillofacial trauma, mandibular fracture, jaw fracture intermaxillar fixation and rehabilitation, recovery, physiotherapy, psychology, nutrition, feeding, diet, care, therapeutic gymnastics and in various combinations of these words in Russian and English. And they also took into account the relevant bibliographic lists. Randomized controlled trials, meta-analyzes, prospective clinical trials were selected based on their significance.

\section{Introduction}

Rehabilitation is the process and system of medical, psychological, pedagogical, socio-economic measures aimed at eliminating or possibly more fully compensating for lifecycle limitations caused by a disorder of health with persistent disorders of the body's functions. Rehabilitation is a part of daily care and reduces the consequences of the disease [39]. The scientific substantiation of the rehabilitation system for patients with injuries of the maxillofacial area is a multidisciplinary problem and is an urgent task of modern medicine due to large economic losses associated with their high prevalence among persons of the most able-bodied age [7,22,32,33,50]. In recent years, the world has been growing the tendency to increase the chronic disability of patients with facial fractures and their rejuvenation. The expressed disadaptation leads in some cases to the refusal of professional activity, while maintaining the work capacity, the efficiency of their work is reduced, which leads to a significant decrease in the quality of life of patients, manifested in the limitation of communication and the impossibility of full participation in social life $[38,60]$.

Damage to the maxillofacial area is accompanied by expressed impairments in the functions of chewing, swallowing, breathing, speech, aesthetics of the face. The consequences of diseases and injuries require long-term comprehensive rehabilitation measures from the side of the maxillofacial surgeon, orthodontist, speech therapist, orthopedist, physiotherapist, dentist therapist, otorhinolaryngologist, ophthalmologist, neurologist [6,17]. In the rehabilitation complex after jaw fractures, such activities as timely and effective fastening of fragments, antimicrobial and general tonic therapy, physical methods of treatment, nutrition, psychological support, exercise therapy and oral hygiene are in the forefront $[39,58]$.

\section{Pharmacological Therapy}

Pharmacological therapy is of greatimportance in the complex treatment of jaw fractures. Usually, patients with fractures are prescribed antibiotics that have the ability to accumulate in bone tissue (linkomycin, sodium fusidine, morphocycline, vibramycin, oleandomycin). In the first 3-4 days after injury, local administration of antibiotics to the area of injury is advisable. Along with antibiotics, sulfonamides and preparations of the nitrofuran series are prescribed [39]. To restore microcirculation prescribe disaggregants, antispasmodics, antihypoxants, and anticoagulants. At the second stage (from three to eight days from the moment of injury), degenerative-inflammatory phenomena 
in the fracture region and the proliferative phase of inflammation develop. In addition to the previous drugs, CT-thyreocalcitonin 5IU is administered intramuscularly to stimulate the proliferative process. In the third stage (9-14 days after trauma), the synthesis of the organic bone matrix is activated. For vigorous synthesis of collagen, the intake of vitamin $\mathrm{C}$ is continued; intramuscular preparations of solutions of iron salts, glutamic acid $1 \mathrm{~g} 3$ times a day are prescribed intramuscularly. To optimize mineralization, calcium preparations are prescribed per os. In the fourth stage (days 15-21), the remodeling of newly formed bone, the membrane-reticulated bone is replaced with fine fiber; bone callus acquires an organic structure. Prescribed regulators of remodeling (CT and calcitriol). At the fifth stage (22-30 days), active remodeling of the bone callus and the construction of osteons complete. Continue to take vitamin D3, calcium preparations and glutamic acid [27]. In addition, the mummiesassil, apilac are successfully used to improve the healing of the bone wound. In order to strengthen the processes of bone tissue regeneration, the use of antioxidants (a complex of vitamins, alpha-tocopherol, ascorbic acid, etc.) in the trauma of the maxillofacial region has been recommended $[10,25,26,36]$. In the treatment of patients with fractures of the mandible, immobilized proteolytic enzymes are used. In the opinion of several authors, the inclusion in the complex therapy of patients with fracture of the mandible of immunopreparations (superlimph, polyoxidonium, immunomodulin, T-activin, Immunal, Dimefosfon) facilitated faster normalization of the general condition of patients and optimization of the wound process $[1,6,26,31]$. To prevent and treat inflammatory processes, intraosseous infusions of a $0.03 \%$ solution of sodium hypochlorite were included in patients with jaw fractures [14]. Important role in the process of regeneration of damaged tissues is played by vitamins and minerals. The organism is not able to fully compensate for these losses through nutrition and its own resources and, therefore, it is necessary to saturate organism of damaged with vitamins, proteins and mineral salts $[42,50,58]$.

\section{Physiotherapy}

To accelerate bone healing, as well as to normalize the condition of local tissues and the entire body for the rehabilitation period, patients are recommended to undergo a course of physiotherapy. Physiotherapy is one of the methods of treatment, which is based on the impact of physical factors (heat, cold, electromagnetic waves, vibration, etc.) that have anti-inflammatory, antibacterial, and regenerative and immunomodulating effects on the body or the damaged area. Currently, in the maxillofacial traumatology, various physical factors are widely used, such as galvanization $[39,54]$, laser therapy $[9,15,19,42,45,51]$, ultrasound therapy $[26,40]$. To reduce the degree of inflammation, physiotherapeutic effects were used - magnetotherapy that reduces edema of tissues and magneto-laser radiation on the projection of the fracture $[10,23,42,54]$, the electric field of UHF and ultraviolet irradiation, electrophoresis of calcium chloride and preparations preventing the development of connective tissue - lidase, ronidase $[12,30,39]$. Hypothermia, which reduces ischemia of tissues and has analgesic and anti-inflammatory effect. Sollux, microwave therapy $[16,20,40,41]$, percutaneous neuroelectrostimulation, electrostimulation of masticatory muscles with exponential current and diadynamic currents, hydrotherapy of the oral cavity, infrared radiation $[24,37,39,42,47]$. Thermal and cold applications in the field of masticatory muscles, pelliotherapy, facial, neck, and collar massage $[2,13,25,28,48]$.

Physiotherapy cannot be considered as the main method of treatment of jaw fracture; however this method allows to significantly accelerating the process of recovery and healing. The use of new physico-pharmacological methods allows stimulating osteoreparative processes in bone tissue and significantly shortening the general terms of rehabilitation of patients.

\section{Nutrition of Patients}

Nutrition of patients with a jaw fracture plays a fundamental role in the complex of therapeutic and rehabilitation measures, affects the clinical outcomes of the disease. A number of authors identified a significant nutritional deficiency in the injured with trauma to the maxillofacial area and proved the influence of nutrition on the indicators of general and local status, quality of life, work capacity and recovery $[8,32,33,44,49,50,55,56,59]$. Patients with jaw fractures are subject to malnutrition due to post-traumatic stress catabolism, which double the body's nutritional needs $[19,58]$. The response is affected by starvation, which is observed after the immobilization of the jaws. Blocking the chewing function of the jaw, the painfulness of the feeding procedure due to the localization of trauma in 1-2 weeks and other factors is the cause of alimentary fasting; the consequence is the development of a number of catabolic changes. Correction of protein, fat, carbohydrate metabolism and other indicators of metabolic processes in human bone fractures is relevant, since restoration of bone integrity is directly related to these parameters $[50,52,53]$. Patients with fractures of the jaws are not able to take regular food due to malfunction of the chewing, sometimes swallowing. A patient with a jaw fracture should be assigned a physiologically complete diet. Full balanced nutrition guarantees, other things being equal, a sufficient protective response of the body. Providing a comprehensive influence on the metabolism and general condition of the body, plays a decisive role in the complex of therapeutic rehabilitation measures. Therapeutic diet should be based on the nature and degree of metabolic disorders of the patient, the food should be mechanically and chemically sparing. Particular attention should be paid to calorie content, protein content, as well as carbohydrates, fats, vitamins, minerals $[27,32,33]$.

In the first phase of the wound process with the predominance of inflammation, acidosis in the wound, development of enzymatic processes in the wound, autolysis, rejection of necrotic tissues, nutrition should increase the body's strength and on the other hand reduce acidosis. In this case, an anti-inflammatory-alkaline diet with reducing of carbohydrates and salt is prescribed. In the second phase of the wound process, with predominance of tissue regeneration processes and in the absence of infectious 
complications, an acidotic-oxidizing diet is prescribed. An alkaline action is in the diet of vegetables, fruits, a highly oxidizing action of proteins (meat, fish, herring, cheese, cottage cheese), as well as bread, cereals, cocoa. By changing the composition of foods in diets, a change in acid-base balance and inter-exchange metabolism is achieved. Changing the direction of interchanges exchanges, thereby affecting the utilization of food products, and therefore, on the organs that produce products of disintegration and cleavage [19].

The need of the injured organism in the energy components of nutrition exceeds the value of the basic metabolism of a healthy person, approximately 30-40 kcal per $1 \mathrm{~kg}$ of weight (normal for healthy people $25-35 \mathrm{kcal} / \mathrm{kg}$ ) $[19,58]$. In the overwhelming majority of cases, additional energy is required to cover additional energy costs arising from the feverish condition, forced muscle tension (for example, stretching in case of bone fractures), gymnastics, hydroprocedures, etc.. Thus, the calorie content of therapeutic rations exceeds $3000 \mathrm{kcal}$. The need for protein in the diet does not decrease from 1.0 to $1.5 \mathrm{~g} / \mathrm{kg}$, as the protein plays an important role in the healing of bones and wounds, which is the main prognostic factor of maxillofacial surgery $[19,53]$.

For patients with maxillofacial trauma, there are 3 diets (tables), which are the same in chemical composition and differ in consistency.

The first jaw (tube) diet is differs with the cream consistency of food. Assign for the entire treatment period, when splints with hook loops are applied and intermaxillary fastening by rubber rings is performed. These patients lost the function of chewing and function of swallowing is bad. The daily energy value of the first jaw table is 3000-4000 calories.

The second jaw diet is characterized by the food of a consistency of thick sour cream. It is indicated to patients who have impaired chewing function, but the function of swallowing is preserved. Assign it at a certain stage of treatment, when it can be removed intermaxillary fixation, or after osteosynthesis of fragments. After the consolidation of the fragments, the patient is assigned a common table (No. 15).

Parenteral nutrition is prescribed to patients who are in an unconscious state for a long period of time, and also as an addition to the enteral. Nutrients can be injected intravenously, subcutaneously, intramuscularly, the intravenous method is often used, the technique of which differs little from intravenous drip administration of medicinal substances. Proteins are input into the body in the form of ready mixtures of polypeptides and amino acids (aminopeptide, hydrolyzate of casein TSOLIPK, hydrolysin L-103, aminocrovin), fats - in the form of ready fatty emulsions (intralipid etc.), carbohydrates - in the form of hypertonic solutions of glucose, fructose or their mixture, sorbitol. A special feature of the nutrition program is the balance between macronutrients: proteins (15-20\%), fats (40-45\%) and carbohydrates (40-55\%), which determines better digestibility and fewer complications. In addition, vitamins ( $\mathrm{C}, \mathrm{B}, \mathrm{A}, \mathrm{K})$, minerals - salts of sodium, potassium, calcium are input. Protein hydrolysates and fatty emulsions can be administered intravenously at a rate of 30-40 drops per minute, solutions of glucose and salts [27,39].

Enteral nutrition is a kind of artificial nutrition in which nutrients (mixtures) are introduced through a probe into the stomach or small intestine if adequate nutrition through the mouth is impossible. Auxiliary nutrition or nutritional support - an additional oral intake of the enteral mixture to meet the physiological needs of the patient with fractures of the jaws when unwillingness or inability to eat in the required amount $[32,33,49]$.

With proper nutrition, the stimulation of the wound process associated with the general health-improving effect on the body as a whole was noted. A dramatic improvement in the health state, blood formulas, a reduction in the length of the hospital stay, and economic efficiency has been proven $[32,49,50,59,61]$.

\section{Special Care}

Special care is the oral cavity care. Hygienic measures include special treatment of the patient's mouth by a doctor during bandaging and mouth cleansing by the patient himself. The state of the oral cavity significantly affects to the healing process of lower jaw fractures $[7,27]$.

From the methods of treatment of lower jaw fractures the immobilization of the lower jaw is most widely used with the help of tooth-splints and intermaxillary rubber traction $[21,50]$. The structural components of splints, ligatures for fixation, rubber rings are the retention points where food remains are retained. This worsens the condition of oral hygiene and creates favorable conditions for the development of inflammatory phenomena in the area of damage, both at the time of fixing the tires, and during the entire time they are found in the oral cavity, inevitable trauma of the marginal part of the periodontal complex occurs. Significant deterioration of the hygienic state of the oral cavity in combination with the traumatic effect of fixation structures leads to the development of pathology in the marginal periodontal region, or aggravates the already existing one. In the literature there are reports that chronic odontogenic and dental pathological foci, infections in the oral cavity contribute to the development of inflammatory complications, are a source of infection of the fracture line and wounds located in the fracture region in patients with fractures of the mandible $[16,21]$.

The formation of the right cleaning skills makes it possible to increase the hygiene efficiency, but however, according to the received data, the dental plaque remains on the oral surface due to the impossibility of cleaning the teeth due to the jaws fastening. Hygienic treatment of the oral cavity with solutions for rinsing does not lead to elimination of the negative situation, but only slightly reduces its activity. The use of rinsing and antiseptics for this purpose significantly improves oral hygiene $[7,22]$.

Medical treatment of the oral cavity consists in thorough cleaning of splints and teeth from food residues by means of irrigation and lavement of the oral cavity with antiseptic solutions. After lavement, the tires are cleaned of food residues 
stuck between the splint, teeth, gum, ligatures and rubber rings. During bandaging, it is necessary to control the position of the splint, the hooks, and the state of the wire ligatures. If there are pressure ulcers from the hooks on the mucous membrane of the lips, gums or cheeks, they must be bent to the appropriate position. Weakened ligatures are twisted and bent to the teeth [27]. Even if the patient is unconscious, he needs at least 2 times a day to wipe his teeth and mucous membrane of the mouth. For this purpose, different antiseptics are used - a solution of furacilin, ethacridine, potassium permanganate, triclosan, octenisept, miramistin chlorhexidine, $3 \%$ hydrogen peroxide solution, and so on. Since during the tiring process, the process of self-cleaning of the mouth is disrupted, lavage of the oral cavity should be carried out at least 8-10 times a day [39].

In studies, it was observed that inflammatory phenomena in the marginal periodontium arose in all patients with fractures of the mandible with splinting, within the dentition, and in many there was a progression of inflammatory-destructive processes in the periodontium. In $89.1 \%$ of cases, these periodontal changes were persistent and persisted with a slight positive dynamics for 6 months [22].

The use of antiseptics and liniments during immobilization and after the removal of their splints helps to eliminate the inflammatory foci and restore the structural and functional properties of the elements of the periodontal complex, which worsened the condition after the effect of wearing splints $[7,23]$.

\section{Training of patients}

Training of patients is an integral component of almost all complex rehabilitation programs. The learning process is aimed at providing the patient and his family members with information about the disease and treatment methods; it promotes the active participation of the patient in the treatment process, forming self-management skills and adherence to therapy. This helps the patient and his family better cope with the disease [4]. The educational process within the framework of an integrated rehabilitation program promotes the introduction of adaptive skills into everyday activities, acquired in the process of rehabilitation, provides a long-term commitment to physical training and a healthy lifestyle.

Training is usually conducted in small groups or individually [39]. The level of patient awareness is assessed before the beginning of the classes, on the basis of which, the necessary volume of the educational program is formed, which is corrected in the process of education. Discussion of medical recommendations also serves as an important component of the rehabilitation program. Usually, such topics are recommended for study: anatomy and physiology of the maxillofacial region, gymnastics - the basic principles of physical training, oral hygiene and care, self-control and self-management of symptoms, nutrition during immobilization, the role of proper nutrition, psychosocial problems, ethical problems and prospects $[4,46]$.

Training should be included in almost all comprehensive rehabilitation programs, so only in some studies did the study of the effectiveness of educating, the positive impact on overall health status and the reduction of the use of health resources $[4,38]$.

\section{Psychological Status}

Patients with a trauma of maxillofacial area in the majority physically high-grade people, at the same time it is seriously suffering people from consciousness of the disfigurement. They naturally become irritable, touchy, usually depressed, inhibited, apathetic, sleepy and a dynamic. Various medical, personal, social and psychological factors influence the adaptation process, and it is often difficult to predict the course of adaptation in many cases $[19,50]$. In this condition, severe asthenic, strong-willed, anxious, frustration, psychopathic symptoms (in the form of conflict, malignancy, quick temper, roughness to relatives), phobic experiences (fear of the outcome of surgical intervention and persistent changes in appearance) are noted in patients with injuries of the maxillofacial area, fear of eating, fear of unpleasant sensations in the stomach from eating), as well as depression, various obsessions associated with eating behavior [43,57].

Feelings of accusation for trauma are realized in placing responsibility for the incident by the patients either on himself or on other people. Investigating patients with facial trauma and linking their psychological state to the circumstances in which these injuries were obtained, Islam S, et al. (2012) concluded that self-incriminating patients are more prone to anxious and depressive manifestations. This is especially true for those who suffered as a result of illegal actions. In addition, injured persons of unlawful acts often have fear of re-attack, in some cases not unreasonable [18]. In patients with chronic alcohol intoxication, the level of reactive anxiety was lower than in other patients. A high probability of having a syndrome of autonomic dysfunction was noted in $62.2 \%$ of patients with jaw injury [29].

In this case, it is important that plastic surgery doctors understand that the ultimate goal of their work, improving the patient's quality of life, is determined not only by their surgical skills, but also by a number of social and psychological factors. A closer attention of doctors to the interpersonal behavior of patients can help in the early detection of patients with maxillofacial trauma, who may experience long-term social problems associated with changing the appearance of the face. The most important step that plastic surgeons can do for their patients to reach the highest level of psychosocial rehabilitation is to develop a consistent and trustworthy relationship with a mental health professional with whom they can confidently and enthusiastically send their patients. Participation of a psychologist can be useful at all stages of treatment. In the acute period of trauma, as a rule, work with relatives of the injured is necessary, after stabilization of the somatic state, work with him becomes actual $[43,57]$.

Most often, special training sessions or support groups are used that focus on recommendations regarding tactics of communication and behavior in stressful situations. Educational 
activities can also improve communication skills. It is advisable to participate in support groups for family members of the patient or friends [19]. An informal discussion of the most important symptoms of the disease and common problems can provide emotional support to patients and their families. A sense of selfefficacy is extremely important for patients, which includes, first of all, the expansion of physical abilities, which is achieved through regular training [4].

\section{Therapeutic Gymnastics}

Forced restriction of motor activity, prolonged immobilization of the jaws, and the possibility of scarring of soft tissue damaged during fracture can lead to such serious complications as contracture of the mandible, ankylosis of the temporomandibular joint, etc. The degree of severity of these disorders depends on the localization of the fracture: in fractures of the condylar process, degenerative changes in both joints are observed more often than with extraarticular fractures. Initially, these disorders have the nature of functional insufficiency, which in 2-7 years can develop into degenerative changes. Unilateral arthrosis develops on the side of damage after single fractures and bilateral - after double and multiple. In addition, all patients with fractures of the lower jaw show marked changes in the masticatory muscles. The ultimate goal of treating jaw fractures is not only to restore the continuity and anatomical shape of the damaged bones, but also to complete the normalization of chewing functions [48,54].

The use of therapeutic physical exercises influences to the improvement of the general condition of the patient, the prevention of complications associated with the hypodynamia and immobilization of the temporomandibular joint, the acceleration of bone fragments consolidation, the faster restoration of these jaws' the function and the reduction of the patient's incapacity for work, as this is an important element of complex treatment and rehabilitation. The fulfillment of these tasks depends to a large extent on how timely the functional treatment is started and whether it is performed correctly [34].

As a rule, for the first 3-4 days, patients with fractures of the jaws are recommended to have a partial bed rest (ward), and in the future - a free motor activity regime. The first days of treatment in a polyclinic involving a patient develop a program of functional rehabilitation. After its understanding, the patient is engaged in physiotherapy exercises at home, visiting the clinic once a week to determine the effectiveness of classes and making adjustments to the program. 3-4 days after immobilization, doctor can prescribe therapeutic gymnastics according to the method of the first period of training. The general severe condition of the patient, fever, fainting or the presence of an acute inflammatory process in the fracture or the risk of bleeding are considered temporary contraindications to the use of exercise therapy [39].

The method of therapeutic gymnastics for fractures of the jaw depends on the periods of bone healing, acting in traumatology, features of immobilization (one or two-jaw splinting, osteosynthesis) and the clinical condition of the patient. For each gymnastics session, general strengthening (general tonic), and special exercises should be included in such sequence and dosage to ensure a general effect on the body and to improve local processes in damaged tissues. The character of general tonic and breathing exercises depends on the regimen of movements and the functional state of the respiratory and circulatory organs of the patient. The basic requirement for the methods of therapeutic gymnastics exercises in fractures of the jaws is the need for strict control of the immobilization conditions until the moment of primary callus formation (the first period of exercise therapy administration). Just a violation of the conditions for reliable fixation of bone debris is the cause of various complications and an increase in the duration of treatment. Avoiding complications, creating the most favorable conditions for synostosis of fractures can only be with the correct use of rest (immobilization) and functional exercise (TE).

The use of special exercises for mimic and masticatory muscles depends on the method of immobilization. Contributing the recovery of the coordinated work of the muscles involved in swallowing, chewing and speech is the primary goal of the first period gymnastics [35].

In the case of a double-maxillary splint, exercises for masticatory muscles are not used because of the inability to open the mouth and the risk of displacement of bone fragments of the immobilized jaw. Doctor can send impulses to reduce the actual masticatory muscles with closed teeth at a slow pace (1-2 seconds interval), without much effort.

In due to the increase in the tone of the masticatory muscles on the side of the fracture and its strengthening under the influence of immobilization, it must be in every possible way help to relax the facial muscles. For this purpose, exercises in the form of stroking, rubbing and kneading for facial muscles, as well as muscles of the tongue and neck are widely used, which promote the improvement of blood supply and lymph flow in the fracture region. If there are no acute inflammatory phenomena in the damaged research area, then on the 7-8th day, it can be begin to massage the face and neck. It should be noted that in muscles, ligaments, there are own receptors that react to contraction: their excitability increases, blood circulation in muscle fibers activates, which significantly affects the functional state of the neuromuscular system, pain is quickly arrested and muscles tightens $[39,48]$.

In the studies of Abdullah A, [3], the results of myotonometry testified that the functional activity of the masticatory muscles is recovered more quickly when the exercises of therapeutic physical training are included in the treatment of fractures of the mandible [3].

With single-jawed splinting or osteosynthesis without intermaxillary fixation, patients already on the 2nd-3rd day are allowed careful movements of the lower jaw in various directions, widely use exercises for mimic muscles, muscles of the tongue and neck, which contribute to improving local blood supply and tone reduction the same musculature 10-15 min. 
In the late postoperative period (7-10th day) the procedure of TE also consists of general strengthening exercises, mainly respiratory exercises, affecting the muscles of the shoulder belt, masticatory and facial muscles, in order to restore their symmetry and coordination of lower jaw movements. Exercises for masticatory muscles are performed by patients not only to open their mouths, but also to recover lateral movements of the jaw, movement in forward. The time of TE procedure increases to $20 \mathrm{~min}$. These exercises necessarily include exercises to increase the mobility of the temporomandibular joint in all directions, gradually increasing the amplitude of motion [35].

Functional load for the temporomandibular joint is strengthened by prescribing individual tasks, which consist of several special exercises performed by the patient independently 7-10 times during the day. Mechanotherapy and passive movements of the lower jaw should not be prescribed together with double-jawed splinting, as this can lead to the formation of a false joint.

After the completion of immobilization (i.e., by the time of formation of the full bone tissue), proceeds to the third stage of treatment of fractures. This is the final stage of recovery treatment, providing for a full medical rehabilitation of the patient and returning him to work. A wide selection of special exercises for masticatory muscles (active, active-passive and with resistance, the use of mechanotherapy), performed with a maximum amplitude of movements (even in presence of moderately severe pain), allows eliminating the existing limitations in the function of the temporal-mandibular joint.

Functional load should also be carried out with great care and be supported by the prescribing of a corresponding diet.General strengthening and breathing exercises are prescribed in a dosage that provides an increase in the activity of the cardiorespiratory system, relevant to the functional capabilities of the patient's body. In presence of regular motor activity, patients' somatic status changes: improves microcirculation, the state of the cardiovascular, respiratory, digestive systems. The method of therapeutic gymnastics exercises provides for individual selection of general tonic, respiratory and special exercises in presence of the motor regime, adequate to the patient's condition $[19,35]$. It is recommended to alternate general strengthening exercises with special exercises in the ratio 2:3.

The therapeutic exercises include breathing and general tonic exercises for all muscle groups in quantity, which does not cause the pulse to accelerate by more than $20-30 \%$ compared to the state of rest. Already on the 4 th-5th day, most patients go from bed rest to open ward regimen. In the initial stage, general strengthening exercises with gymnastic sticks, dumbbells, exercise and then gradually add jumping rope, lunges, pushups, squats, twists, hoops, morning jogs etc. While performing gymnastic exercises, patients can feel fatigue at the beginning, then, under the influence of regular physical exertion, ease of movement, strength, high spirits, improvement of endurance and motor activity are experienced [38,39]. Regular physical exertion in a gentler mode and with the control of a diet, in patients improves both physical states and psychopathological manifestations of the disease. Due to physical exertion, most patients with trauma in the maxillofacial region may experience an emotional lift, also an increase in self-esteem, which is the effectiveness performed of the therapeutic and rehabilitation measures, determined by the dynamics and improvement of the physical and mental state of the patients [38].

Thus, therapeutic gymnastics improves the general condition of the patient, stimulates reparative processes in damaged bones and soft tissues, prevents complications associated with immobilization (osteomyelitis, false joint, contracture) and increases the functional efficiency of operations or orthopedic treatment $[4,19,34,35,38,39]$.

\section{Conclusion}

Rehabilitation measures improve physical activity and functional status, improve general health status, reduce the severity of local symptoms of the underlying disease, and, possibly, have a positive effect on the progression of the disease. Timely treatment and constant care will help to survive this unpleasant episode without significant losses.

\section{References}

1. Aghasyan VA. Mechanisms of the formation of stress immunodeficiency in fractures of the mandible and methods for their correction. Abstract of dissertation candidate of med sciences. 2012;24.

2. Alekseev SB. Rehabilitation of injured patients with fractures of the lower jaw, via peloidotherapy: abstract of dissertation candidate of med Sciences Poltava. 2003;22p.

3. Amro Abdullah. Clinical picture and treatment of fractures of the mandible in adults in different age periods. Abstract of dissertation candidate of medical sciences. St Petersburg. 2013;27.

4. Belevsky AS. Rehabilitation of patients with pulmonary pathology. J Pulmonology and allergology. 2007;4:14-17.

5. Bogatov VV, Kuritsin VM. Ultrasound and echondral osteogenesis in the experiment. Dentistry. 2004;№2:4.

6. Boymuradov Sh AA. Improving the diagnosis and treatment of patients with combined injuries of the bones of the facial skeleton: Abstract of dissertation of DSc. Tashkent. 2012;24p.

7. Boymuradov Sh A, Bobamuratova DT. Condition of the paradontium in patients with jaw fracture. J Stomatologiya. Tashkent. 2016;2:75-79.

8. Boymurodov Sh A, Bobamuratova DT, Kurbonov EC. Change in body weight by season, in patients with a fracture of the lower jaw. J Stomatologiya. Tashkent. 2016;2:69-74.

9. Vasilyeva EB. Laser therapy and photophoresis in the complex treatment of Temporomandibular Pain Dysfunctional Syndrome: Dis. candidate of medical sciences. Moscow. 2002;152p.

10. Gerasimenko MYu, Filatova EV, Nikitin AA, Stuchilov VA, Kosyakov MN, Grishina NV. New aspects of rehabilitation of patients with posttraumatic defects and deformations of the maxillofacial region. Questions of balneology, physiotherapy and exercise therapy. $2000 ; 6: 27-29$ 
11.Gerasimenko MYu. Features of physiotherapy in dentistry Almanach of clinical medicine. 2000;2:436-444.

12. Gerasimenko MYu. Physical factors in the complex rehabilitation of children with congenital clefts of the upper lip and palate. Diss DSc in medicine. Moscow. 1996;354.

13. Datsko AA, Tetyukhin DV. Implementation of modern principles of treatment of damage in the maxillofacial region. J Stomatology 2003;1:17-19.

14. Dolgova IV, Efimov YuV, Afanasyeva OYu, Malyukov AV, Mukhin VN. Innovative technologies in the rehabilitation of patients with fractures of the mandible. Volgograd Scientific Medical Journal 2011;1:46-48.

15. Durnova EA. Comparative analysis of the functional activity of blood and oral neutrophils in patients with a purulent-inflammatory process in the oral cavity. J Stomatology. 2005;3:32.

16. Erokina NL. Modern methods of examination and substantiation of pathogenetic treatment of inflammatory periodontal diseases in patients with fractures of the mandible: abstract of dis. DSc in med Volgograd. 2008;22.

17. Zheleznaya YuK, Zheleznyi SP. Complex rehabilitation of patients after bone reconstructive surgery in the maxillofacial region. J of Syberian med sciences. 2015;1:2-6.

18.Zakharchenko DA, Dozortseva YeG. Psychological reactions and predisposing factors in patients with combined and multiple physical trauma, injured as a result of illegal actions. Journal of Psychology and Law. 2013;3:1-11.

19. Kabakov BD, Rudenko AT. Nutrition for patients with facial and jaw injuries and caring for them L - Medicine. 1977;135.

20. Karaev PH. Rehabilitative microzonal physiotherapy of soft tissues of the cervico-facial region. Abstract of diss, cand. Medical sciences. Moscow. 1997;25.

21. Kuzhonov ZhT. Stomatological status of patients with fractures of the lower jaw and its influence on the development of inflammatory complications. Abstract of dis candidate of medical sciences. Nalchik. 2005;22.

22. Kutsenko RV. The condition of the marginal periodontium of patients in the treatment of fractures of the lower jaw with the use of orthopedic and surgical methods. Abstract of dis. candidate of medical sciences- Moscow. 2012;24.

23.Lavrischeva GI, Gorokhova GP. Questions of reparative bone tissue regeneration. J Stomatology. 2003;3:65-66.

24. Makarenkov VV, Reinauli JIB. Use of infrared laser radiation in the prevention of inflammatory complications in fractures of the mandible. Materials of the I International Conference of Maxillofacial Surgeons. St Petersburg. 1996;67-68.

25. Malichenko NV, Nikitin AA, Savitskaya KI, Filatova EV. Koletex in the treatment of odontogenic phlegmon. In the collection. Modern issues of physiotherapy and balneology. M. 2004;63.

26. Mubarakova LN. Pathogenetic substantiation of the new approach in complex treatment of suppurative processes of maxillofacial area. Abstract diss candidate of medical sciences. Kazan. 2008;25.
27. Fracture of the lower jaw. Available from: https://medi.ru/ klinicheskie-rekomendatsii/perelom-nizhnej-chelyusti_14165

28.Prokhonchukov AA, Zhizhina HA, Balashov AN. Laser physiotherapy of dental diseases. J Stomatology. 1995;6:23-31.

29. Pudov AN. Spiridonova EA. Drobyshev AYu, Bobrinskaya IG, Lagutin BM. Psychological status in patients with acute injury of the lower jaw. Journal of General Reanimatology. 2012;8:31-36.

30. Robustova TG, Gubin MA, Tsarev VN. Ways of prevention and treatment of inflammatory diseases of the maxillofacial region and their complications. Stomatology. 1995;1:31-32.

31. Tarchokova EM. Clinical and immunological evaluation of the effectiveness of complex treatment of patients with odontogenic phlegmons and fractures of the lower jaw with the use of local immunocytokinotherapy. Abstract of disser candidate of medical sciences. 2011;24.

32.Tegza NV. Medico-economic justification for the use of dry nutrient mixtures in the nutrition of servicemen with injuries and diseases of the maxillofacial region in medical institutions of the Ministry of Defense of the Russian Federation. Dis candidate of medical sciences. 2008;32.

33. Telnykh RYu. The use of biologically active food additives in the complex treatment of open traumatic fractures of the lower jaw. Diss Candidate of medical sciences. 2008;30.

34.Physical rehabilitation in fractures of the jaws and bones of the facial skeleton. Available from: http://intranet.tdmu.edu.ua/ data/kafedra/internal/fiz_reabil/classes_stud/ru/stomat/ptn/ Physical\%20rehabilitation/

35. Physical rehabilitation in maxillofacial injuries. Available from: http://travelexpress.lt/fizicheskaja-reabilitatsija-v-travmatologiii-ortopedii/fizicheskaya-reabilitatsiya-pri-chelyustno-litsevykhtravmakh

36. Khamitova GC. Ultraphonophoresis and photophoresis of osteoregenerator preparations for traumatic injuries of the facial skeleton. Abstract of diss Cand of med sciences. Moscow. 2005;25.

37. Khasanov AI, Abdullaev ShYu. The significanse of the level of lipid peroxidation products for predicting traumatic osteomyelitis of the lower jaw. Stomatology. 2002;2:27-29.

38.Tseryabina VV. The use of a complex of rehabilitation measures for patients with craniocerebral trauma in the system of "inpatient - aftercare at home". Abstract of Diss. Candidate of Biological Sciences. Moscow. 2009:25.

39. Sharov DS, Ivanyuk AS. Rehabilitation after fractures and injuries.

40.Yablonskaya NI. Morphofunctional characteristics of peloidotherapy in the complex treatment of fractures of the lower jaw: Dis. Candidate of medical sciences. Simferopol; 1990;170.

41.Yaroshkevich AV. Dynamic changes in regional muscular blood flow and intensity of mineralization of the formed callus in different ways of treatment of fractures of the mandible: abstract of dis. candidate of medical sciences. Moscow; 1990;19.

42.Al-Shawi A. Open-packing method for the severely comminuted fractured mandible due to missile injury. Br J Oral Maxillofac Surg. 1995;33(1):36-39. 
43. Auerbach SM, Laskin DM, Kiesler DJ, Wilson M, Rajab B, Campbell TA. Psychological factors associated with response to maxillofacial injury and its treatment. J Oral Maxillofac Surg. 2008;66(4):755-761. doi: 10.1016/j.joms.2007.12.006

44.Christiansen B, King BJ. The effect of mandibular fracture treatment on nutritional status. J Oral Maxillofac Surg. 2016:74(9):30.

45. Dederich DN, Bushick RD. Lasers in dentistry. J Am Dent Assoc. 2004;135(2):204-212.

46.DiMaria-Ghalili RA, Mirtallo JM, Tobin BW, Hark L, Van Horn L, Palmer CA. Challenges and opportunities for nutrition education and training in the health care professions: Intraprofessional and interprofessional call to action. Am J Clin Nutr. 2014;99(5 Suppl):1184S-1193S. doi: 10.3945/ajcn.113.073536

47. Jung HD, Jung YS, Park JH, Park HS. Recovery pattern of mandibular movement by active physical therapy after bilateral transoral vertical ramus osteotomy. J Oral Maxillofac Surg. 2012;70(7):e431-e437. doi: 10.1016/j.joms.2012.02.033

48.Khalifa GA, El-Kilani NS, Shokier HM. Physiotherapy maneuver is critical to recover mouth opening after pediatric trauma. J Oral Maxillofac Surg. 2016;74(12):2465-2479. doi: 10.1016/j. joms.2016.07.026

49. El Khatib K, Gradel J, Danino A, Mouaffak M, Malka G. Enteral feeding by nasogastric tube in mandibular fracture osteosynthesis. Rev Stomatol Chir Maxillofac. 2005;106(1):3-5.

50.Elamin N. Some physiological changes following intermaxillary fixation. A thesis submitted in partial fulfilment for the requirements of the degree of MSc. Sudan. 2006;y:10-15.

51. Santinoni CD, Oliveira HF, Batista VE, Lemos CA, Verri FR. Influence of low-level laser therapy on the healing of human bone maxillofacial defects: A systematic review. J Photochem Photobiol B. 2017;169:8389. doi: 10.1016/j.jphotobiol.2017.03.004

52.Gordon PE, Lawler ME, Kaban LB, Dodson TB. Mandibular fracture severity and patient health status are associated with postoperative inflammatory complications. J Oral Maxillofac Surg. 2011;69(8):2191-2197. doi: 10.1016/j.joms.2011.03.071
53. Hamid HE, Azlina A, Igzeer YK. The role of protein deficiency in the healing of mandibular fractures in rabbit model. International journal of pharmacy and pharmaceutical sciences. 2014;6(2):352357.

54.Anke van der Merwe. The development of a physiotherapy intervention program for closed or open reduction and / or internal fixation of mandibular condyle fractures. A research report submitted in fulfillment of the requirements of the M.Sc. Physiotherapy degree. 2013.

55.Javad Y, Saeed H, Mohammad Ali G, Bahram Pourghasem G, Amin $\mathrm{N}$, Yousef K. Evaluation of changes in anthropometric indexes due to intermaxillary fixation following facial fractures. J Dent Res Dent Clin Dent Prospects. 2016;10(4):247-250. doi: 10.15171/ joddd.2016.039

56. Kayani SG, Ahmed W, Farooq M, Rehman AU, Nafees Q, Baig AM. Weight loss due to maxillomandibular fixation in mandibular fractures. Pak Oral Dent J. 2015;35(3):374-376.

57. Pitak-Arnnop P, Hervé C, Coffin JC, Dhanuthai K, Bertrand JC, Meningaud JP. Psychological care for maxillofacial trauma patients: a preliminary survey of oral and maxillofacial surgeons. J Craniomaxillofac Surg. 2011;39(7):515-518. doi: 10.1016/j. jcms.2010.11.007

58. Raymond JF, Robert VW, Norman JB. Oral and Maxillofacial trauma. 4th ed. Elsevier. 2013;33:752.

59. Ono S, Ishimaru M, Ono Y, Matsui H, Fushimi K, Yasunaga H. Impact of Body Mass Index on the Outcomes of open reduction for mandibular fractures. J Oral Maxillofac Surg. 2016;74(5):1024.e1e5. doi: 10.1016/j.joms.2016.01.008

60.Sen P, Ross N, Rogers S. Recovering maxillofacial trauma patients: the hidden problems. J Wound Care. 2001;10(3):53-57.

61.Tappenden KA, Quatrara B, Parkhurst ML, Malone AM, Fanjiang G, Ziegler TR. Critical role of nutrition in improving quality of care: an interdisciplinary call to action to address adult hospital malnutrition. J Acad Nutr Diet. 2013;113(9):1219-1237. doi: 10.1016/j.jand.2013.05.015 